\title{
CRÉDITO PREVIDENCIÁRIO - RECURSO ADMINISTRATIVO - DEPÓSITO PRÉVIO
}

- Constitucionalidade da exigência de depósito prévio para admissibilidade de recurso administrativo.

\author{
Ministério da Previdência e Assistência Social \\ Parecer CJ n. 1.297/98
}

\section{DESPACHO DO MINISTRO}

Em 11 de maio de 1998

\section{Aprovo.}

\section{WALDECK ORNÉLAS}

PARECER CJ/n² 1.197/98

Estou de acordo e submeto à elevada consideração de Vossa Excelência o Parecer/CJ/n² 1.297/98 da lavra da Dra. Cristina dos Reis Emygdio da Silva, sobre a constitucionalidade da exigência do depósito recursal como condição de admissibilidade do recurso administrativo.

Faço-o nos termos e para os fins do disposto nos incisos II e III do art. 11 e art. 42 da Lei Complementar $n^{2} 73$, de 10 de fevereiro de 1993.

Brasília, 11 de maio de 1998. (José Bonifácio Borges de Andrada). Consultor Jurídico.

EMENTA: Crédito Previdenciário. Medida Provisória no 1.608-13 de 2 de abril de 1998. Exigibilidade o depósito recursal como condição de admissibilidade do recurso administrativo. Inexistência de violação aos princípios do contraditório e da ampla defesa. Não constitui garantia constitucional o duplo grau de jurisdição administrativa.

Trata-se de discussão sobre a exigibilidade do depósito prévio correspondente a $30 \%$ ao valor do crédito previdenciário, como condição de admissibilidade do recurso administrativo. A matéria já apreciada pelos nossos tribunais tem sido objeto de algumas controvérsias.

2. Há os que alegam que a exigência do depósito prévio estabelecido no artigo $10 \mathrm{da}$ Medida Provisória $n^{2}$ 1.608-13, de 02 de abril de 1998, para o conhecimento do recurso ad- ministrativo, constitui flagrante violação aos princípios constitucionais. Na tentativa de sustentar a inconstitucionalidade da exigência legal, argumentam que na esfera administrativa as garantias constitucionais devem ser interpretadas conjuntamente a fim de se assegurar o devido processo legal sem obstáculos ao contraditório e a ampla defesa.

3. Sustentam, ainda, que o depósito prévio caracteriza ato lesivo, pois consubstancia cerceamento de defesa e óbice ao acesso do contribuinte ao reexame da decisão proferida em processo administrativo. Devendo-se, por conseguinte, eliminar a exigência da comprovação do depósito prévio correspondente a trinta por cento da exigência fiscal, para o conhecimento do recurso.

4. Cumpre transcrever, preliminarmente, o artigo 10 da Medida Provisória n 1.608-13, de 02 de abril de 1998, que assim dispōe:

“Em se tratando de processo que tenha por objeto a discussão de crédito previdenciário, o recurso de que trata este artigo somente terá seguimento se o recorrente, pessoa juridica, instruí-lo com prova de depósito, em favor do Instituto Nacional de Seguro Social - INSS de valor correspondente a trinta por cento da exigência fiscal definida na decisāo."

5. Ora, o fundamento deste dispositivo assenta-se na necessidade de agilizar a cobrança dos créditos previdenciários, visto que muitas vezes, observamos a interposição de sucessivos recursos apenas com o desiderato de obter efeito suspensivo em relação à exigibilidade do crédito, adiando-se, dessa forma, a sua cobrança definitiva.

6. A limitação da interposição do recurso 
administrativo não pode por si só ser considerada contrária ao devido processo legal. $\mathrm{O}$ fato de os princípios constitucionais referentes ao devido processo legal serem estendidos ao processo administrativo, não significa de forma alguma que este é ilimitado e incondicional.

7. Ressalta-se que a decisão em processo administrativo, uma vez desfavorável ao administrado, este tem livre acesso ao Judiciário. Nesse sentido, bem salientou a ilustre Juíza da Primeira Vara Federal do DF ao indeferir a liminar no Mandado de Segurança $\mathrm{n}^{2}$ 98.8994-2/DF, in verbis:

$\mathrm{Na}$ verdade, a garantia constitucional de livre acesso ao Judiciário é que, de certa forma, torna legítima a restrição administrativa e embora atribuída à esta exigência uma novidade, na verdade, encontra-se consolidada, inclusive, no âmbito da Justiça obreira.

8. Ante a polêmica das questōes suscitadas, é mister fazer um breve estudo sobre o conteúdo e alcance dos princípios do contraditório, ampla defesa e duplo grau de jurisdição, trazidos à colação.

\section{PRINCÍPIO DO CONTRADITÓRIO E DA AMPLA DEFESA}

9. A Constituição Federal estabelece que "aos litigantes, em processo judicial ou administrativos, e aos acusados em geral são assegurados o contraditório e ampla defesa, com os meios e recursos a ela inerentes" (art. $5 \%$, inciso LV). O dispositivo é claro ao determinar que o princípio alcança tanto os processos judiciais como os administrativos.

10. Tal inovação foi trazida pela Carta de 1988, visto que a Constituição Federal de 1969 só conferia esta garantia ao processo penal. O princípio do contraditório é manifestação clara do Estado Democrático de Direito, pois ao garantir aos litigantes o contraditório e a ampla defesa, protege por conseguinte, $o$ direito de ação e o direito de defesa.

11. Nelson Nery Júnior in Princípios do Processo Civil na Constituição Federal esclarece: "Por contraditório deve entender-se, de um lado, a necessidade de dar-se conheci- mento da existência da ação e de todos os atos do processo às partes, de outro, a possibilidade de as partes reagirem aos atos que lhe sejam desfavoráveis."

12. José Cretella Júnior in Comentários à Constituição de 1988, Vol. I, ensina: “ $A$ regra da "ampla defesa" abrange a regra do "contraditório", completando-se os princípios que as informam e que se resumem no postulado da liberdade integral do homem diante da prepotência do Estado". O mestre Celso Ribeiro Bastos complementa: " Por ampla defesa deve entender-se o asseguramento que é feito ao réu de condições que lhe possibilitem trazer para o processo todos os elementos tendentes a esclarecer a verdade" (Curso de Direito Constitucional, $18^{\mathrm{a}}$ ed., p. 226).

13. Dessa maneira, torna-se imprescindível analisar o caso concreto a fim de se verificar o atendimento aos princípios acima citados. Ora, se o contraditório e a ampla defesa buscam assegurar tratamento isonômico a ambas as partes, o que se mostra fundamental no processo administrativo é a possibilidade de o administrado, após o lançamento do crédito, ter a oportunidade de produzir todas as provas que julgar necessária, bem como apresentar a defesa, ocorrendo esta bilateralidade, não há que se falar em violação aos princípios constitucionais.

14. Observa-se que, no processo administrativo fiscal previdenciário, após a lavratura da Notificação Fiscal de Lançamento de Débito - NFLD é facultado ao notificado o direito de apresentar defesa no prazo de 15 (quinze) dias, sem nenhuma limitação ou requisito de admissibilidade (art. 37, parágrafo único da Lei $n^{2}$ 8.212, de 1991). $E$, neste momento, a Administraçāo está claramente preservando e observando o princípio constitucional da ampla defesa e do contraditório.

\section{PRINCÍPIO DO DUPLO GRAU DE JURISDIÇÃO}

15. O princípio do duplo grau de jurisdição surgiu para uma maior efetivação do binômio segurança-justiça. $O$ inconformismo do sucumbente e a possibilidade de erro em deci- 
sões de única instância gerou a necessidade de que as decisões judiciais fossem reapreciadas por um órgão de jurisdição de hierarquia superior à daquele que proferiu a decisão.

16. A Constituição do Império, 1824, garantia o duplo grau de jurisdição ilimitadamente, ou seja, era vedado ao legislador ordinário restringir os casos de cabimento de recurso de apelação, pois a parte, desde que quisesse, deveria ter a sua causa apreciada pelo Tribunal de Relação (hoje, Tribunal de Justiça). Entretanto, com o advento das Constituiçōes posteriores, essa garantia absoluta ao duplo grau de jurisdição sofreu restriçōes. Não se fala mais em garantia ao duplo grau, o que se observa é que a Constituição Federal apenas menciona a existência de Tribunais e confere-lhes competência recursal.

17. Esta limitação se deu face da necessidade de os litígios não se prolongarem no tempo, utilizando-se do pretexto de adquirir maior segurança e justiça nas decisões judiciais, e dessa forma, desprestigiando a eficácia da justiça em detrimento da paz social. A Constituição Federal vigente, apesar de fazer uma previsão para o princípio do duplo grau de jurisdição ao dispor que os tribunais possuem competência para julgar originariamente e em grau de recurso, nāo estabelece a "garantia" ao duplo grau de jurisdição.

18. É fundamental a distinçāo entre "garantia" e "previsão", nesse sentido, afirma Nelson Nery Júnior: Não havendo garantia constitucional do duplo grau, mas mera previsāo, o legislador infraconstitucional pode limitar o direito de recurso, dizendo, por exemplo, nāo caber apelação nas execuções fiscais de valor igual ou inferior a 50 OTNs (art. 34, da Lei n. 6.830/80) ou, ainda, não caber recurso dos despachos (art. 504, CPC).

Esses artigos não são inconstitucionais justamente em face da ausência de "garantia" do duplo grau de jurisdição. Entretanto, não poderá haver limitação ao cabimento do recurso especial ou extraordinário, como era permitido no sistema revogado (art. $119, \S$ I, CF de 1969), porque a atual Constituição Federal não estipulou nenhuma restrição. Os requisitos estão no próprio texto constitucional e somente eles devem ser exigidos do recorrente para que sejam conhecidos os recursos extraordinário e especial.

(Princípios do Processo Civil na Constituiçāo Federal, p. 149).

19. Depreende-se dos ensinamentos acima que a inexistência da garantia constitucional ao duplo grau de jurisdição permite que sejam estabelecidas regras de admissibilidade dos recursos, limitando ou até mesmo impedindo a possibilidade de recorrer.

20. Ora, se nāo constitui afronta à Constituiçāo a limitaçāo ao recurso judicial, não há que se indagar da inconstitucionalidade de limitação ao recurso administrativo, visto que a matéria decidida na esfera administrativa ainda pode ser examinada no âmbito judicial.

21. No nosso ordenamento jurídico verificamos inúmeras hipóteses onde há a restrição e até mesmo a impossibilidade de recurso, vejamos:

a) As decisōes do Tribunal Superior Eleitoral são irrecorríveis (salvo quando contrariarem a Constituição Federal ou denegarem habeas corpus e mandado de segurança - art. $121, \S 32, \mathrm{CF} / 88$ );

b) Lei de Execuçāo Fiscal não admite apelação quando o valor da causa for inferior a 50 OTNs (art. 34, caput);

c) Não se admite recurso das decisões proferidas pelos Juizados Especiais criados pela Lei n 9.099, de 26 de setembro de 1995, para o Tribunal de Justiça e para o Superior Tribunal de Justiça.

d) $\mathrm{O}$ art. 93 da Lei n 8.212/91 impōe como requisito para o seguimento do recurso, de processo originado por infração de obrigação acessória previdenciária, o depósito de $100 \%$ do valor da multa atualizada monetariamente;

e) não cabimento de recurso de despachos de mero expediente (art. 504, CPC);

f) quando a condenação dos dissídios individuais corresponde ao valor de até 10 vezes o salário de referência regional o recurso só será admitido mediante o prévio depósito da respectiva importância (Art. 899, CLT);

g) quando for imposta multa por infração de leis e regulamentos trabalhistas, o recurso só terá seguimento se instruído com o comprovante do depósito da multa (art. 636, $§ 1$ 을, CLT) etc. 
22. O Senhor Ministro Octávio Gallotti, no RE 169.077-I/MG, abordou o tema:

\section{VOTO}

Exerceu a ora recorrente, e plenamente, o seu direito de defesa prévia à homologação do auto de infração, porfiando, ainda assim, na queixa contra o condicionamento da interposição do recurso ao depósito da importância da multa que lhe fora imposta.

Mas os recursos hierárquicos inerentes a essa defesa são os instituídos e regulados por lei, de modo algum se vislumbrando, no texto da Constituiçāo, a pretensa garantia do duplo grau de jurisdição administrativa.

Dessa forma entendeu o Plenário do Supremo Tribunal, ao examinar, perante os mesmos itens XXXV, LIV e LV do art. 5 da Carta de 1988, a argüição de inconstitucionalidade do art. 83 da Lei $n^{\circ} 8.212-91$, com a redação que lhe fora dada pela Lei $n^{\circ} 8.870-94$, onde se erigiu, em condição de recorribilidade de atos de imposição de multas por infração de regra de legislação previdenciária, a prova do depósito do respectivo valor, monetariamente atualizado. Ao proferir voto vencedor pelo indeferimento da cautelar requerida pela Confederação Nacional dos Trabalhadores Metalúrgicos, deixou claro, naquela assentada, o emitente Ministro Sepúlveda Pertence, então presidente da Corte:

"Também peço vênia ao eminente Relator para indeferir a cautelar.

Consideraria da mais alta relevância a argüição, se se exigisse o depósito para a garantia da defesa prévia à decisāo da Autarquia. Não é o caso. O que se exige é o depósito para um recurso administrativo, já proferida a decisão da Autarquia. Ora, como o devido processo legal não impõe sequer o direito à existência do recurso administrativo, não vejo de que maneira o condicionamento do seu exercício de depósito poderia afastar a garantia do devido processo legal."

(ADIN 1.049, sessão de 18-5-95)

Coerente com esse magistério, foi a decisão do Plenário no Recurso Extraordinário $n^{2}$ 210.246 (sessāo de 12.11.97).
Fiel a essa linha de pensamento, para cuja prevalência contribui meu voto, não conheço do recurso extraordinário.

EMENTA: Multa por degradação do meio ambiente. Exercida defesa prévia à homologação do auto de infração, não padece de vício de inconstitucionalidade a legislação municipal que exige o depósito prévio do valor da multa como condição ao uso de recurso administrativo, pois não se insere, no Carta de 1988, garantia do duplo grau de jurisdição administrativa.

Precedentes: ADI 1049, SESSÃO DE 18-595, RE 210.246, 12.11.97. Contrariedade não configurada, do disposto nos incisos $X X X V$, LIV e LV do art. 5 da Constituição.

Recurso extraordinário de que, por esse motivo não se conhece.

(RE No 169.077-1-MG, Primeira Turma, $05.12 .97)$ - grifei.

23. O Supremo Tribunal Federal em outras oportunidades ressaltou a possibilidade de restrição aos recursos administrativos, inclusive o condicionamento dos recursos ao depósito prévio, veja-se:

EMENTA: - Constitucional. Previdenciário. 13. Salário: sua não integração no salário-de-contribuição para o cálculo de beneficio. Recurso: obrigatoriedade do depósito da multa imposta. Beneficios: prazo de carência. Abono de permanência: extinçāo. Peculio. Extinção. Lei 8.212, de 1991, § 7. do artigo 28 e art. 93 com a redação da Lei 8.870/94. Art. 25, inciso II e artigo 82 da Lei 8.213, de 1991, com a redação da Lei $n$. 8.870, de 1994.

1. Suspensão cautelar da eficácia do art. 93 da Lei 8.212, de 1991, com a redação da Lei $8.870 / 94$, que estabelece que "o recurso contra a decisão do INSS que aplicar multa por infração a dispositivo da legislação previdenciária só terá seguimento se o interessado o instruir com a prova do depósito da multa atualizada monetariamente, a partir da data da lavratura." (Voto vencido do Relator).

II - Indeferimento da cautelar relativamente aos demais dispositivos legais acoimados de inconstitucionais. (Voto do Relator).

III - Indeferimento da cautelar relativamente a todos os dispositivos acoimados de 
inconstitucionais: $\S 7$. do art. 28 e art. 93 da Lei 8.212/91, com a redação da Lei 8.870/94, bem assim do inciso II do art. 25 e do art. 82 da Lei 8.213, de 1991, com as alteraçōes da Lei 8.870 , de 1994 .

(Adin 1049, Rel. Min. Carlos Velloso, DJ de 25.08.95)

EMENTA: Extraordinário. Infração às normas trabalhistas. Processo administrativo. Contraditório e ampla defesa. Penalidade. Notificação. Recurso perante a DRT. Exigência do depósito prévio da multa. Pressuposto de admissibilidade e garantia recursal. Afronta ao art. 5', LV, CF. Inexistência.

Informativo do STF $\mathrm{n}^{2}$ 92:

Obrigatoriedade do depósito de multa imposta:

$O$ tribunal, entendendo recepcionado pela

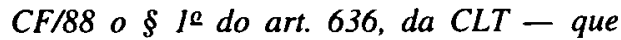
determina que o recurso administrativo contra a imposição de multa por infração das leis reguladoras do trabalho só terá recurso administrativo contra a imposição de multa por infração das leis reguladoras do trabalho só terá seguimento se o interessado o instruir como a prova do depósito da multa - conheceu e deu provimento, por maioria de votos, a recurso extraordinário da União Federal para reformar o acórdão do TRF $1^{\sharp}$ Região que entendeu que o prévio depósito do valor discutido pelo empregador violaria os princípios da ampla defesa e do contraditório.

(RE 210.246, Rel. Min. Nelson Jobim, 12.11.97)

24. O Ministro Maurício Corrêa no RE 223.436-3, em recente decisão (DJ de 30 de abril de 1998, p. 46 - Seção I) foi esclarecedor, in verbis:

DECISĀO: Autuada apela fiscalização do trabalho, a empresa, ora recorrente, apresentou defesa administrativa que não foi acolhida.

2. Pretendendo recorrer, impetrou mandado de segurança para que o recebimento do seu recurso não fosse condicionado ao prévio recolhimento da multa aplicada.

3. A Terceira Turma do Tribunal Regional Federal da $4^{4}$ Região negou provimento ao recurso de apelaçāo interposto, firmando o entendimento de que a exigência do depósito prévio da multa como pressuposto para a interposição do recurso, previsto em norma infraconstitucional, não acarreta ofensa aos princípios do contraditório e da ampla defesa.

4. Assim, com fundamento no art. 102, III, "a" da Constituição Federal, interpôs-se o presente recurso extraordinário, alegando que o acórdão impugnado negou vigência aos preceitos constitucionais do art. 5\%, II, XXXV, LIV, LV e art. 59.

5. O recurso não comporta provimento. $A$ matéria controvertida encontra-se pacificada no âmbito desta Corte, na forma da ementa extraída dos autos do RE 210.373-0, DJU de 06.03.98, por mim relatado, verbis:

EMENTA: Extraordinário. Infraçāo às normas trabalhistas. Processo administrativo. Contraditório e ampla defesa. Penalidade. Notificação. Recurso perante a DRT. Exigência do depósito prévio da multa Pressuposto de admissibilidade e garantia recursal. Afronta ao art. 5, LV, CF. Inexistência.

1. Processo administrativo. Imposição de multa. Prevê a legislação especial que, verificada a infraçāo às normas trabalhistas e lavrado o respectivo auto, o infrator dispõe de dez dias, contados do recebimento da notificação, para apresentar defesa no processo administrativo (art. 629, $\$ 3^{\circ}, C L T$ ) $e$, sendo esta insubsistente, exsurge a aplicação da multa mediante decisâo fundamentada (art. 635, CLT). Não observância ao princípio do contraditório e ampla defesa: alegação improcedente.

2. Recurso administrativo perante a DRT. Exigência de comprovação do depósito prévio. Pressuposto de admissibilidade e garantia recursal.

2.1. Ao infrator, uma vez notificado da sanção imposta em processo administrativo regular, é facultada a interposição de recurso no prazo de dez dias, instruído com a prova do depósito prévio da multa (art. 636, $\$ 2^{\circ}, C L T$ ), exigência que se constitui em pressuposto de sua admissibilidade.

2.2. Violação ao art. 5e, $L V, C F$. Inexistên- 
cia. Em processo administrativo regular, a legislação pertinente assegurou ao interessado o contraditório e a ampla defesa. A sua instrução com a prova do depósito prévio da multa imposta não constitui óbice ao exercicio do direito constitucional do art. 5e, $L V$, por se tratar de pressuposto de admissibilidade e garantia recursal, visto que a responsabilidade do recorrente, representada pelo cuto de infração. está aferida em decisāo fundamentada. Recurso conhecido e provido.

6. O depósito deve existir para que tenha seguimento o processo administrativo, o que sem sombra de dúvida não limita o direito de recorrer. pois a multa constitui garantia recursal e não somente penalidade, dado que aferida a responsabilidade em decisão fundamentada.

7. O devido processo legal, observados a ampla defesa e o contraditório, aplica-se também aos processos administrativos, e a presente hipótese compatibliza-se com tal instituto, uma vez respeitada a fase anterior do art. $629 \mathrm{da}$ CLT.

Assim, na linha dos precedentes desta Corte, por não constituir violação ao princípio da ampla defesa a exigência do depósito prévio da multa não para posterior interposição do recurso administrativo, previsto no art. 636 ,
$\S 1^{10}$ da CLT, visto que, em fase anterior, assegurou-se o contraditório, de conformidade com o disposto na legislação pertinente, nego seguimento ao presente recurso, com fundamento no art. 21 , § $1^{\circ}$ do RISTF. (grifei).

25. Ressalta-se, ao final, que consoante as regras de interpretaçāo das normas processuais, que determinam a sua aplicação imediata, inclusive aos processos em curso, o referido depósito é exigível e obrigatório a partir da vigência da Medida Provisória, ainda que já iniciado o prazo recursal.

26. Dessa forma, ante as manifestações da doutrina e do Pretório Excelso, restou comprovada a constitucionalidade da exigência referida na Medida Provisória. Não há, portanto, que se falar em ofensa aos princípios do contraditório e ampla defesa, quando for exigido comprovante de depósito como requisito de admissibilidade de recurso administrativo.

À apreciação superior. Brasília, 11 de maio de 1998. Cristina dos Reis Emygdio da Silva. Assessora Jurídica. Aprovo. À consideração do Senhor Consultor Jurídico. Brasília, 11 de maio de 1998. Antônio Glaucius de Morais. Coordenador-Geral de Direito Previdenciário. Procurador Autárquico.

(Of. n² 118/98) 